\title{
The Significance of Vascular Pathogenesis in the Examination of Corticobasal Syndrome
}

\author{
Anna Dunalska ${ }^{1 *}$, Julia Pikul ${ }^{2}, K^{2}$ atarzyna Schok ${ }^{2}$, Katarzyna Anna Wiejak ${ }^{2}$ and \\ Piotr Alster ${ }^{1}$ \\ 'Department of Neurology, Medical University of Warsaw, Warsaw, Poland, ${ }^{2}$ Students' Scientific Association of the \\ Department of Neurology, Medical University of Warsaw, Warsaw, Poland
}

OPEN ACCESS

Edited by: Sabina Capellari, University of Bologna, Italy

Reviewed by: Deepali Mathur,

University of Valencia, Spain Luca Marsili, University of Cincinnati, United States

*Correspondence: Anna Dunalska adunalska@gmail.com

Received: 16 February 2021 Accepted: 06 April 2021 Published: 04 May 2021

Citation:

Dunalska A, Pikul J, Schok K, Wiejak KA and Alster P (2021) The Significance of Vascular Pathogenesis in the Examination of Corticobasal

Syndrome.

Front. Aging Neurosci. 13:668614. doi: 10.3389/fnagi.2021.668614
Corticobasal syndrome (CBS) is a clinical entity, classified as an atypical Parkinsonism, characterized by both motor and higher cortical dysfunctions. The clinical manifestation of CBS is associated with several pathologies, among which corticobasal degeneration (CBD) is the most common. The aim of our study was to elaborate on the possible vascular pathogenesis of CBS and consider types of vascular lesions in these cases. Several cases of vascular CBS are described in the literature. The majority of presented patients were affected by internal carotid artery (ICA) stenosis and ischemic strokes; few cases were associated with vascular malformations or autoimmune diseases. Vascular CBS is preceded by an abrupt onset. The clinical manifestation does not significantly differ with non-vascular CBS. Patients with vascular CBS are usually elderly; often with coexistent hypertension, dyslipidemia and diabetes mellitus. Inferring from our observations, cerebral hypoperfusion can play a significant role in neuropathological changes in neurodegenerative diseases. To the best of our knowledge paper is the first comprehensive review of vascular CBS and we are positive that our observations show that further research concerning the vascular pathogenesis of tauopathy atypical Parkinsonism is required.

Keywords: tauopathies, corticobasal syndrome, corticobasal degeneration, vascular, neurodegeneration

\section{INTRODUCTION}

Corticobasal syndrome (CBS) is a clinical entity, classified as an atypical Parkinsonism. The research in the topic of CBS is relatively recent. It was primarily described as corticobasal degeneration (CBD), as Rebeiz et al. $(1967,1968)$ presented studies about then so called "corticodentatonigral degeneration with neuronal achromasia." Neurodegeneration was, thereafter, incorporated in the nomenclature of this phenomenon and used to describe the etiology of the symptoms, which are nowadays comprised in a clinical entity - CBS (Gibb et al., 1989). CBS is characterized by both motor and higher-cortical dysfunctions. Armstrong et al. (2013) presented the criteria for the diagnosis of CBS, which indicate two main domains of this syndrome: cortical dysfunction with orobuccal/limb apraxia, cortical sensory deficit, alien limb phenomena and extrapyramidal dysfunction expressed as: limb rigidity or akinesia, limb dystonia, limb myoclonia. The diagnosis of probable CBS can be made if two of cortical dysfunction features and two of extrapyramidal dysfunction features, with asymmetric distribution, are present, whereas possible CBS is characterized by one of cortical dysfunction features and one of extrapyramidal dysfunction features, which can affect the body symmetrically. Abovementioned criteria partly 
correspond with another diagnostic tool (Mathew et al., 2011) known as Cambridge criteria, in which akinetic rigid syndrome, limb apraxia and speech/language impairment serve as main symptoms and are accompanied by minor ones: focal or segmental myoclonus, symmetrical dystonia, alien limb phenomenon, cortical sensory loss or dyscalculia, frontal executive dysfunction and visuospatial deficits.

Epidemiological data concerning CBS is limited, but based on conducted studies its incidence is estimated to be less than 1 per $1,00,000$ patients per year. Commonly the age of onset of CBS is between 50 and 70 . The only known risk factor is advanced age (Grijalvo-Perez and Litvan, 2014).

CBS is associated with CBD, but these terms must be distinguished, as the first one is a clinical diagnosis, while the second one is a neuropathological term (Saranza et al., 2019). CBD describes a pathology in which abnormally hyperphosphorylated $4 \mathrm{R}$ tau protein is deposited in the somatosensory cortex, premotor, supplementary motor cortices, brainstem and basal ganglia (Ali and Josephs, 2018). The clinical manifestation of this disease depends on the localization of neuronal loss and tau pathologies in the brain (Saranza et al., 2019). Prevalent clinical phenotype of CBD is CBS; however, CBD may also manifest with progressive supranuclear palsy syndrome (PSP), frontotemporal dementia (FTD), Alzheimer's like dementia $(\mathrm{AD})$, the frontal behavioral-spatial syndrome and the non-fluent/agrammatic variant of primary progressive aphasia (Armstrong et al., 2013; Ali and Josephs, 2018). On the other hand, CBS can also be related to the spectrum of other neuropathologies such as AD, PSP, Pick's disease (PiD), fronto-temporal lobar degeneration with ubiquitin-TDP-43positive inclusions (FTLD-TDP), Lewy body disease (LBD), and Creutzfeldt-Jakob disease (CJD) and globular glial tauopathy (Boeve, 2011; Parmera et al., 2016; Marsili et al., 2018).

Because of the complexity of the abovementioned phenomena and their mutual superimposition, it should be mentioned that PSP and CBD have overlapping phenotypes and therefore are often difficult to differentiate. The new approach of "probable 4-repeat (4R)-tauopathy" nomenclature has been introduced for joint clinical diagnosis of PSP and CBD by Respondek et al., who reached high specificity of this new diagnostic category in their study. Both, CBD and PSP, are 4R tauopathies, however, the localization of neurodegeneration and deposits of tau pathologies in them vary, especially in the case of astrocytic tauopathy deposits (Respondek et al., 2020). In CBD the most characteristic glial lesion are astrocytic plaques, whereas in the PSP more characteristic is the tufted astrocyte. Astrocytic plaques are seen especially in the cortex, but also in the caudate and putamen. In PSP tufted astrocytes mostly accumulate in precentral gyrus, striatum and superior colliculus. Another neuropathological feature which differentiates PSP and CBD is presence of ballooned neurons in CBD, whereas in PSP they are rare. In PSP more common than in CBD is presence of coiled bodies, which are oligodendroglial tau inclusions (Irwin, 2016; Parmera et al., 2016). Many of genetic risk factors and pathological mechanisms are common for CBD and PSP. Clinically, they can present like Richardson's syndrome, CBS, frontal cognitive/behavioral presentation, and speech/language dysfunction (Respondek et al., 2020). In comparison to $4 \mathrm{R}$ tauopathies, $\mathrm{PiD}$ is characterized by the presence of three-fold (3R) tau isoforms, while in Alzheimer's disease both $3 \mathrm{R}$ and $4 \mathrm{R}$ isoforms are found in the filaments (Goedert et al., 2017). Thereupon, it can be concluded, that CBS can be a manifestation of $4 \mathrm{R}$ and $3 \mathrm{R}$ tauopathies.

Among the typical features of CBS there is also an asymmetric distribution of the motor symptoms. According to Di Stasio et al. (2019) this kind of typical pattern corresponds with decreased glucose metabolism and cerebral blood flow in positron emission tomography (PET) and single photon emission computed tomography (SPECT), as the affected side of frontoparietal cortex, caudate, putamen, thalamus, pons, and cerebellum is often contralateral to the clinically more symptomatic side (Abe et al., 2016).

\section{MATERIALS AND METHODS}

A comprehensive literature search for articles was performed using the PubMed database. The following keywords were used: "CBS," "CBD," CBS diagnostic criteria," "vascular CBS," "vascular progressive supranuclear palsy," "vascular tauopathies," "vascular Alzheimer's disease," "vascular Parkinsonism," "tauopathies," "cerebrovascular frontotemporal lobar degeneration." The search was limited to human subjects with language restriction to English and French from 1994 to December 31, 2020. The snowball strategy, including a manual search of the references listed by studies retrieved from the online databases and from previously published reviews, was also performed to identify potential additional studies. The following inclusion criteria were used: studies published in the English and French language, and studies available in full text.

\section{RESULTS}

\section{Vascular Pathogenesis of Tauopathies}

Tauopathies are neurodegenerative diseases, which are morphologically, biochemically, and clinically heterogeneous, however, their common feature is the accumulation of abnormal tau protein in the brain (Tan et al., 2018). They comprise following disorders: $\mathrm{AD}$, a $3 \mathrm{R} / 4 \mathrm{R}$ tauopathy, and frontotemporal lobar degeneration subtype tau (FTLD-tau) group, which includes: PSP, CBD, argyrophilic grain disease (AGD), all considered 4R tauopathies, and PiD, a 3R tauopathy (Kovacs, 2015; Arendt et al., 2016; Irwin, 2016; Kovacs, 2017). Interestingly, Mulroy et al. (2020) described the broad spectrum of tauopathies, in which the accumulation of tau protein is secondary to the pathophysiology such as head trauma, ischemia, oxidative stress and alterations in protein synthesis. It should be emphasized that the number of tau-related disorders is constantly increasing. Numerous attempts have been made in order to assess the incidence and potential effect of vascular abnormalities in abovementioned diseases. Although some patients with FTLD had cerebrovascular changes, the neuropathological studies did not find the association between FTLD and cardiovascular 
disease (CVD) (Baborie et al., 2011; De Reuck et al., 2012). Vascular PSP can be identified in the presence of CVD, when cardinal pathologic features indicating idiopathic PSP cannot be found. Clinical symptoms of vascular PSP can differ from those presented in idiopathic PSP. Multiple cerebrovascular lesions were found in vascular PSP, especially in thalamus and basal ganglia, while the main areas affected in patients with idiopathic PSP are substantia nigra, subthalamic nuclei, and periaqueductal gray matter (Josephs et al., 2002). The most common risk factors in vascular PSP are hypertension and smoking (Rabadia et al., 2019). Moreover, male gender is predominant in patients with vascular PSP (Winikates and Jankovic, 1994) and it can indicate the role of male gender in CVD. In addition, hypertension can cause deterioration of tau-mediated motor impairment. However, vascular or white matter lesions are responsible for the exacerbation (Díaz-Ruiz et al., 2009). The vascular PSP called "Mokri syndrome" is also worth mentioning. It is a rare disorder appearing after ascending aorta surgery. The typical symptoms include supranuclear gaze palsy, gait imbalance and dysarthria (Mokri et al., 2004; Tisel et al., 2020). AD differs from other tauopathies in the presence of $\beta$-amyloid peptide, but not only the neurodegenerative basis of this disease but also the correlation between $\mathrm{AD}$ and $\mathrm{CVD}$ attracts interest of the researchers in this field (Liesz, 2019). According to de la Torre, chronic brain hypoperfusion, which can be caused by hypertension or carotid atherosclerosis, can initiate AD (De La Torre, 2018). Studies showed that reduced oxygen level leads to increased $\beta$-secretase activity and induces the formation of $\beta$-amyloid protein. Moreover, CVD can lead to local hypoxia or even ischemia, which induce expression of hypoxia-inducible factor-1 $\alpha$ (HIF -1 $\alpha$ ). According to recent studies HIF- $1 \alpha$ stimulates the expression of $\beta$-secretase (Khan and Davies, 2008; Salminen et al., 2017). Furthermore, several cardiovascular genes that increase the risk of $\mathrm{AD}$ have been identified by genetic studies (Broce et al., 2019). Interestingly, AD in comparison to FTLD has a higher prevalence of CVD (Toledo et al., 2013). As mentioned above, AD can present clinically with CBS. Clinical symptoms such as tremors, myoclonus and early memory impairment can suggest CBS-AD (Chand et al., 2006; Hu et al., 2009). Magnetic resonance imaging (MRI) findings showed atrophy not only of subcortical gray nuclei and basal ganglia, but also temporoparietal region that is characteristic for CBS-AD (Josephs et al., 2010). We found it worth mentioning because there are many studies on vascular pathogenesis of $\mathrm{AD}$ and that can suggest the association between CVD and CBS.

\section{Causes of Vascular CBS Carotid Artery Occlusion}

Carotid artery occlusion has been reported to be one of the potential causes of CBS. In the case report described by Engelen et al. neurological symptoms (Table 1) were associated with decreased left internal carotid artery (ICA) flow. Acute appearance of these symptoms suggest vascular, rather than neurodegenerative, etiology, as CBD tends to have insidious onset (Engelen et al., 2011). Marques et al. described the occurrence of unexplained hemiplegia with consecutive homolateral CBS in two patients with metabolic disorders and prior endarterectomy due to ICA stenosis. In spite of the absence of visible ischemic lesions in these patients, it can be hypothesized that iatrogenic transient hypoxia and consequent pathologic change in neuronal networks of cortex and basal ganglia resulted in CBS (Marques et al., 2018). Additionally, other authors Vitt et al. (2020); Miyaji et al. (2013), and Kim et al. (2009) described patients with symptoms suggesting CBS with ICA stenosis (Table 1). In the case observed by Kim et al. (2009), authors assumed that lesions in brain MRI were typical for progressive ischemia due to large vessel steno-occlusion, although the mechanism is unclear. Abovementioned cases, despite being relatively uncommon, suggest that the ICA occlusion and consecutive depletion of the cerebral blood flow in certain brain regions, can lead to the occurrence of CBS-like symptoms, ranging from motor abnormalities to higher-cortical dysfunctions. Blood flow reduction, due to stenotic ICA, was linked to pathologic state of increased oxygen extraction, called misery perfusion, in which maximal vasodilation enables the oxygen supply. It cannot be excluded that this kind of changes lead to selective dendritic and cortical neuronal injury, manifesting among others in CBSlike symptoms (Yamauchi et al., 2007; Yamauchi et al., 2017). Some patients, who developed symptoms of CBS, suffered from hypertension. Marques et al. (2018) suggested that dysregulation of the cerebrovascular system and hypertension together lead to an increase of cerebral blood flow, which could potentially cause brain injury and support vascular etiology of CBS.

\section{Ischemic Incidents}

Evidence of cerebrovascular disease, in a form of ischemic areas, as a potential cause of CBS, have been provided by the research conducted by Koga et al. (2019). Postmortem examination of 217 patients with CBS diagnosis in 3 individuals displayed presence of infarcts in the brain regions (Table 1), potentially significant for CBS etiology. Another study involving postmortem examination was performed by Thal et al. (2015) and resulted in a finding that $33.3 \%$ of the patients with antemortem diagnosis of CBD had infarctions present in the brain, whereas no evidence of hemorrhage lesions was observed in this sample. Moreover, Kim et al. (2009) described vascular lesions of the ischemic character, located in fronto-temporo-parieto-occipital lobes in a patient with CBS. Ischemic pathogenesis of CBS was also mentioned in a case report by Peters et al., who described the occurrence of unilateral rigidity, micrographia and gait disturbances in a 56-year-old patient. Those symptoms, primarily ineffectively treated with levodopa/benserazide and selegiline, eventually emerged as caused by ischemic lesion located in the left cerebral peduncle, in close proximity to the substantia nigra and nucleus ruber (Peters et al., 2001). Further information about vascular etiology of CBS symptoms derives from the article by Kreisler et al. (2007). All of the patients had motor and highercortical dysfunction suggesting CBS and related ischemic lesions in the brain (Table 1). Another study, by Ling et al. (2010), assessed the possible pitfalls in CBD diagnosis and supplied with further information about potential vascular causes of CBSlike symptoms, as one patient's right hand apraxia and alien limb phenomena eventually emerged as being partly attributable 
TABLE 1 | Characteristics of the patientswith vascular CBS.

\begin{tabular}{|c|c|c|c|c|}
\hline Authors & Clinical manifestation & Imaging and additional tests & Pathological examination & Patients' characteristics \\
\hline Engelen et al. (2011) & $\begin{array}{l}\text { - Right-sided limb-kinetic apraxia and } \\
\text { extrapyramidal dysfunction }\end{array}$ & $\begin{array}{l}\text { - Left frontoparietal atrophy with multiple } \\
\text { subcortical hyperintensities, left ICA } \\
\text { stenosis }\end{array}$ & - No data & $\begin{array}{l}\text { - } 64 \text {-year-old man, cigarette smoker with } \\
\text { hypertension }\end{array}$ \\
\hline Marques et al. (2018) & $\begin{array}{l}\text { - Myoclonus, left-sided apraxia, akinetic-rigid } \\
\text { syndrome, rapid cognitive decline } \\
\text { - tremor of the left superior limb with rigidity } \\
\text { and bradykinesia, verbal and visual memory } \\
\text { impairment, visuoc-onstructive apraxia and } \\
\text { left-sided hemineglect }\end{array}$ & $\begin{array}{l}\text { - } 80 \% \text { right ICA stenosis, right carotid } \\
\text { endarterectomy, decreased metabolism in } \\
\text { the right frontoparietal area and right } \\
\text { striatum } \\
\text { - left ICA thrombosis, right carotid } \\
\text { endarterectomy, decreased metabolism in } \\
\text { the right frontoparietal area and right } \\
\text { striatum }\end{array}$ & $\begin{array}{l}\text { - No data } \\
\text { - no data }\end{array}$ & $\begin{array}{l}\text { - 67-year-old man, history of two episodes } \\
\text { of transient amaurosis of the right eye, } \\
\text { diabetes mellitus, hypertension and } \\
\text { dyslipidemia } \\
\text { - } 71 \text {-year-old man, history of a stent for } \\
\text { ischemic heart disease and a left middle } \\
\text { cerebral artery stroke } 7 \text { years previously, } \\
\text { diabetes mellitus, hypertension and } \\
\text { dyslipidemia }\end{array}$ \\
\hline Vitt et al. (2020) & $\begin{array}{l}\text { - cognitive decline, gait abnormality, } \\
\text { asymmetric Parkinsonism and alien limb } \\
\text { phenomena }\end{array}$ & $\begin{array}{l}\text { - right ICA stenosis, right MCA territory } \\
\text { infarcts with surrounding encephalomalacia } \\
\text { and atrophy }\end{array}$ & - No data & $\begin{array}{l}\text { - } 81 \text {-year-old man with history of diabetes, } \\
\text { hypercholesterolemia and hypertension }\end{array}$ \\
\hline Miyaji et al. (2013) & $\begin{array}{l}\text { - Right-sided limb-kinetic apraxia, } \\
\text { constructional apraxia, right upper limb } \\
\text { rigidity and a wide-based gait with small } \\
\text { steps, aphasia, dysarthria, and right } \\
\text { hemiparesis }\end{array}$ & $\begin{array}{l}\text { - Left ICA stenosis, decreased cerebral } \\
\text { blood flow in the left hemisphere and } \\
\text { crossed cerebellar diaschisis, ischemic } \\
\text { lesions in the left corona radiata and the left } \\
\text { watershed area }\end{array}$ & - No data & -65-year-old man with diabetes mellitus \\
\hline Kim et al. (2009) & $\begin{array}{l}\text { - Left hand dystonia, generalized myoclonus, } \\
\text { mild left side weakness, bilateral limb } \\
\text { ataxia, dressing and ideomotor apraxia, } \\
\text { rapid progressive memory loss and } \\
\text { tendency to fall }\end{array}$ & $\begin{array}{l}\text { - Diffuse cortical high signal intenities with } \\
\text { intravascular enhancement at the frontal, } \\
\text { parietal, occipital and temporal lobes, } \\
\text { bilaterally, but predominantly in the right } \\
\text { hemisphere, steno-occlusions of the right } \\
\text { distal ICA and MCA and severe stenosis of } \\
\text { the left MCA }\end{array}$ & - No data & $\begin{array}{l}\text { - 75-year-old woman with hypertension, } \\
\text { angina pectoris and bipolar disease }\end{array}$ \\
\hline Koga et al. (2019) & $\begin{array}{l}\text { - Spastic-dystonic left hemiparesis and } \\
\text { hyperreflexia with clonus, left-sided apraxia, } \\
\text { dystonic posture on the left extremities } \\
\text { - cognitive impairment, marked asymmetric } \\
\text { ideomotor apraxia in both upper extremities } \\
\text { (left > right), rigidity (left > right), } \\
\text { bradykinesia, myoclonus, possible eyelid } \\
\text { apraxia or blepharospasm, neck rigidity, } \\
\text { horizontal and up-gaze nystagmus, } \\
\text { pseudobulbar affect, lower body negative } \\
\text { myoclonus } \\
\text { - asymmetric rigidity (right > left), lower } \\
\text { muscle weakness (right > left), a Babinski } \\
\text { sign on the right, slurring of speech, } \\
\text { word-finding difficulties and short-term } \\
\text { memory problems }\end{array}$ & $\begin{array}{l}\text { - Asymmetric right hemisphere atrophy in } \\
\text { the frontal, temporal, parietal and occipital } \\
\text { lobes, right lateral ventricle dilation, } \\
\text { hyperintensities of the periventricular region } \\
\text { (gliosis), low signal changes in the right } \\
\text { basal ganglia, right cerebral peduncle and } \\
\text { right aspect of the pons } \\
\text { - deep white matter hyperintensities } \\
\text { consistent with small vessel disease, } \\
\text { chronic lacunar infarcts, and mild cerebral } \\
\text { atrophy } \\
\text { - 90\% left ICA stenosis, chronic infarct in the } \\
\text { left frontal lobe, left frontal hypoactivity, } \\
\text { diffuse left cerebral hypoactivity, including } \\
\text { decreased activity in the left basal ganglia, } \\
\text { thalamus and the right cerebellum }\end{array}$ & $\begin{array}{l}\text { - No arteriosclerotic small vessel disease, } \\
\text { Alzheimer-related pathology insignificant, } \\
\text { tau, } \alpha \text {-synuclein, and TDP- } 43 \text { pathology not } \\
\text { detected, infarcts in right hemisphere, } \\
\text { Wallerian degeneration in right hemisphere } \\
\text { - arteriosclerotic small vessel disease } \\
\text { present, Alzheimer-related pathology } \\
\text { insignificant, tau, } \alpha \text {-synuclein, and TDP-43 } \\
\text { pathology not detected, infarcts in left } \\
\text { hemisphere, Wallerian degeneration in left } \\
\text { hemisphere } \\
\text { - arteriosclerotic small vessel disease } \\
\text { present, Alzheimer-related pathology } \\
\text { insignificant, tau, } \alpha \text {-synuclein, and TDP-43 } \\
\text { pathology not detected, infarcts in both } \\
\text { hemispheres, Wallerian degeneration in left } \\
\text { hemisphere }\end{array}$ & $\begin{array}{l}\text {-69-year-old man with homocystinuria, } \\
\text { dyslipidemia, diabetes mellitus and } \\
\text { migraine } \\
\text { - 82-year-old woman with atrial fibrillation, } \\
\text { hypertension, hyperlipidemia, diabetes } \\
\text { mellitus, aortic atherosclerosis, congestive } \\
\text { heart failure, coronary artery disease, } \\
\text { peripheral vascular disease, chronic kidney } \\
\text { failure and obstructive sleep apnea } \\
\text { - 69-year-old man with hypertension, } \\
\text { hyperlipidemia, stroke at age 51, severe } \\
\text { peripheral and ischemic heart disease with } \\
\text { two cardiac stents, peripheral cyanosis, } \\
\text { claudication and colorectal cancer }\end{array}$ \\
\hline
\end{tabular}




\begin{tabular}{|c|c|c|c|c|}
\hline Authors & Clinical manifestation & Imaging and additional tests & Pathological examination & Patients' characteristics \\
\hline Kreisler et al. (2007) & $\begin{array}{l}\text { - Myoclonus and rigidity of the left upper } \\
\text { limb, akinesia, loss of the swing of the left } \\
\text { arm, apraxia and dysarthria, apraxia of the } \\
\text { upper left limb, kinetic cerebral syndrome of } \\
\text { the upper limbs } \\
\text { - resting tremor, akinesia and rigidity of the } \\
\text { left upper limb, gait instability, amimia, } \\
\text { hypophonia, parkinsonian dysarthria, } \\
\text { Parkinsonism, myoclonus, apraxia, } \\
\text { dystonia, alien limb phenomena and } \\
\text { cognitive decline } \\
\text { - akinetic/rigid parkinsonian syndrome of the } \\
\text { left side, gait abnormalities, myoclonus of } \\
\text { the right upper extremity, apraxia and left } \\
\text { hemiasomatognosia, right-left agnosia, } \\
\text { dyscalculia } \\
\text { - akinesia, rigidity, dystonia, tremor of the } \\
\text { upper right limb, gait abnormalities, left } \\
\text { apraxia, left spatial neglect, dyscalculia, } \\
\text { dysexecutive syndrome } \\
\text { - left Parkinsonism, mostly unilateral rigidity, } \\
\text { akinesia, dystonia, left apraxia and } \\
\text { dysexecutive syndrome }\end{array}$ & $\begin{array}{l}\text { - Right hemisphere: ischemic lesions of } \\
\text { frontal, pre- and post-central, temporal gyri, } \\
\text { centrum semiovale, internal capsule; } \\
\text { posterior fossa: ischemic lesions of } \\
\text { cerebellar hemispheres and the left part of } \\
\text { the mesencephalon } \\
\text { - right hemisphere: ischemic lesions of the } \\
\text { pre- and post-central gyri, centrum } \\
\text { semiovale, putamen and caudate nucleus; } \\
\text { left hemisphere: ischemic lesions in pre- } \\
\text { and post-central gyri, parietal cortex, } \\
\text { centrum semiovale, internal capsule, } \\
\text { putamen and caudate nucleus; posterior: } \\
\text { ischemic lesions of the pons } \\
\text { - right hemisphere: ischemic lesions of } \\
\text { frontal, pre- and post-central gyri, medial } \\
\text { and lateral parts of the parietal lobe, insular } \\
\text { cortex, occipital lobe, anterior, median and } \\
\text { posterior parts of the centrum semiovale } \\
\text { and putamen. left hemisphere: ischemic } \\
\text { lesions of frontal, pre- and post-central gyri, } \\
\text { the inferior parietal lobulus, insular cortex, } \\
\text { anterior, median and posterior parts of the } \\
\text { centrum semiovale, putamen, and } \\
\text { thalamus } \\
\text { - right hemisphere: ischemic lesions of frontal } \\
\text { gyri, medial and lateral parts of the parietal } \\
\text { lobe; and the median and posterior parts of } \\
\text { the centrum semiovale. left hemisphere: } \\
\text { ischemic lesions of the median and } \\
\text { posterior parts of the centrum semiovale } \\
\text { - right hemisphere: ischemic lesions of the } \\
\text { anterior and median parts of the centrum } \\
\text { semiovale, putamen, globus pallidus, } \\
\text { caudate nucleus; left hemisphere: ischemic } \\
\text { lesions of the anterior, median and posterior } \\
\text { parts of the centrum semiovale, putamen, } \\
\text { globus pallidus }\end{array}$ & $\begin{array}{l}\text { - No data } \\
\text { - no data } \\
\text { - no data } \\
\text { - no data } \\
\text { - no data }\end{array}$ & $\begin{array}{l}\text {-64-year-old woman with mixed } \\
\text { cryoglobulinemia type II, purpura of the } \\
\text { lower limbs, and arthritis of the hip } \\
\text { - } 77 \text {-year-old women with hip replacement, } \\
\text { breast neoplasia and hysterectomy } \\
\text { - } 76 \text {-year-old woman with hypertension } \\
\text { - 68-year-old woman with mammary } \\
\text { neoplasia and subocclusive fecal syndrome } \\
\text { - 73-year-old woman with hypertension, } \\
\text { hypercholesterolemia and transient global } \\
\text { amnesia }\end{array}$ \\
\hline
\end{tabular}


TABLE 1 | Continued

\begin{tabular}{|c|c|c|c|c|}
\hline Authors & Clinical manifestation & Imaging and additional tests & Pathological examination & Patients' characteristics \\
\hline Ling et al. (2010) & $\begin{array}{l}\text { - Right hand apraxia and alien limb } \\
\text { phenomena }\end{array}$ & $\begin{array}{l}\text { - Infarction of the left middle cerebral artery } \\
\text { territory in addition to the characteristic } \\
\text { pathological changes associated with CBD }\end{array}$ & $\begin{array}{l}\text { - Cerebral infarction of the left middle } \\
\text { cerebral artery territory in addition to the } \\
\text { characteristic pathological changes } \\
\text { associated with CBD }\end{array}$ & -- \\
\hline Morris and Lees (1999) & $\begin{array}{l}\text { - Parkinsonism with hypomimic facies, } \\
\text { shuffling gait, left-sided akinetic-rigid } \\
\text { syndrome, vertical supranuclear gaze palsy, } \\
\text { left-sided upper motor neuron facial } \\
\text { weakness and asymmetric upper limb } \\
\text { rigidity and bradykinesia (left arm more } \\
\text { severely affected than the right one), left } \\
\text { mild pyramidal weakness and apraxia }\end{array}$ & $\begin{array}{l}\text { - Multiple infarcts in the cerebral } \\
\text { hemispheres and basal ganglia with } \\
\text { prominent lesions in the right parietal lobe } \\
\text { and head of the left caudate nucleus }\end{array}$ & - No data & - 44-year-old woman with migraine \\
\hline Martino et al. (2006) & $\begin{array}{l}\text { - Ideomotor and limb-kinetic apraxia } \\
\text { bilaterally, dyscalculia, difficulty in } \\
\text { distinguishing left from right, walk with short } \\
\text { steps, stooped posture, flexed dystonic } \\
\text { posture of the right arm, retropulsion, } \\
\text { hypomimia, intellectual deterioration }\end{array}$ & $\begin{array}{l}\text { - Periventricular white matter changes, } \\
\text { diffuse cerebral cortico-subcortical atrophy, } \\
\text { several infarcts in both hemispheres, } \\
\text { including striatum }\end{array}$ & $\begin{array}{l}\text { - Non-specific severe gliosis of cortex, white } \\
\text { matter and deep gray nuclei, without } \\
\text { evidence of vasculitis, } \\
\text { Immunohistochemical stains for amyloid } \\
\text { and tangles (A4 and Tau) were negative }\end{array}$ & $\begin{array}{l}\text { - 56-year-old woman with hypertension and } \\
\text { migraine }\end{array}$ \\
\hline Hashimoto et al. (2018) & $\begin{array}{l}\text { - Asymmetric upper limb akinesia and rigidity } \\
\text { more severe on the left side, dystonia of the } \\
\text { left arm and leg, slow gait with absent arm } \\
\text { swing, bilateral limb-kinetic apraxia } \\
\text { prominent on the left side, }\end{array}$ & $\begin{array}{l}\text { - Subcortical white matter ischemic } \\
\text { changes, marked cortical atrophy that was } \\
\text { prominent in the bilateral central areas, and } \\
\text { several small infarcts in deep white matter } \\
\text { of both hemispheres }\end{array}$ & - No data & - 53-year-old woman \\
\hline Lee et al. (2014) & $\begin{array}{l}\text { - Progressive clumsiness of the left hand, } \\
\text { cognitive decline, numbness of the 4th and } \\
\text { 5th finger on the left hand, dysarthria, } \\
\text { memory loss and difficulty in calculation } \\
\text { and mapping, oculomotor apraxia, dystonic } \\
\text { posturing of both hands, moderate rigidity } \\
\text { in only the left upper extremity, moderate } \\
\text { bradykinesia bilaterally (more severe in the } \\
\text { left upper and lower extremities), ideomotor } \\
\text { and limb-kinetic apraxia bilaterally }\end{array}$ & $\begin{array}{l}\text { - Widespread cortical atrophy that was more } \\
\text { severe in the right fronto-parieto-occipital } \\
\text { region without apparent changes in the } \\
\text { periventricular white matter }\end{array}$ & - No data & - 47-year-old man \\
\hline
\end{tabular}




\section{TABLE 1 | Continued}

\begin{tabular}{|c|c|c|c|c|}
\hline Authors & Clinical manifestation & Imaging and additional tests & Pathological examination & Patients' characteristics \\
\hline Bihari et al. (2016) & $\begin{array}{l}\text { - Alexia, apraxia, agrammatism of the } \\
\text { speech with mild anomia, executive } \\
\text { dysfunction, hypokinesis with mild right } \\
\text { upper limb rigidity, and postural instability } \\
\text { and wide-based gait with decreased right } \\
\text { upper limb synkinesis }\end{array}$ & $\begin{array}{l}\text { - The hypointense subpial rim around the } \\
\text { medial temporal structures and the pons, } \\
\text { the right-sided thalamic cavernoma }\end{array}$ & $\begin{array}{l}\text { - Aberrant vascular structures with } \\
\text { hemosiderin deposition and gliosis }\end{array}$ & $\begin{array}{l}\text { - 56-year-old woman with hypertension and } \\
\text { migraine }\end{array}$ \\
\hline Takase et al. (2017) & $\begin{array}{l}\text { - Moderate cognitive decline, small voice, left } \\
\text { dominant lead pipe rigido-spasticity, mild } \\
\text { left hemiparesis, small steppage gait, } \\
\text { micrographia, left limb-kinetic apraxia and } \\
\text { constructional apraxia }\end{array}$ & $\begin{array}{l}\text { - Multiple dural arteriovenous fistulas } \\
\text { (DAVFs) around the superior sagittal sinus, } \\
\text { dilatation of the superficial temporal } \\
\text { arteries, bilateral hyperintense lesions in the } \\
\text { subcortices, striata, thalami, and pyramidal } \\
\text { tracts of the pons, microbleeds in the same } \\
\text { regions, areas of severe hypoperfusion in } \\
\text { the right fronto-parieto-temporal lobes, } \\
\text { striatum, and thalamus }\end{array}$ & - No data & - 75-year-old man \\
\hline Jain and Khan (2017) & $\begin{array}{l}\text { - Spastic speech, asymmetric rigidity ( } \mathrm{L}>\mathrm{R}) \text {, } \\
\text { myoclonus, dystonia with fixed twisting } \\
\text { posture of left hand associated with alien } \\
\text { limb phenomenon, bilateral cerebellar signs }\end{array}$ & $\begin{array}{l}\text { - Asymmetrical hyperintensities in } \\
\text { fronto-occipito-parietal region (cortical } \\
\text { ribboning) with subtle hyperintensities also } \\
\text { present in left temporal lobe } \\
\text { - anti-TPO antibody titers raised to } 590 \mathrm{IU} / \mathrm{ml}\end{array}$ & - No data & - 70-years-old female \\
\hline Sheetal et al. (2016) & $\begin{array}{l}\text { - Difficulty in finding words, amnesia for } \\
\text { recent events, inattention, difficulty in } \\
\text { walking, psychomotor withdrawal, } \\
\text { bradykinesia, agrammatical, effortful } \\
\text { speech, four limb rigidity, more on the right } \\
\text { side, focal myoclonus of the right upper } \\
\text { and lower limbs during rest, aggravated by } \\
\text { action and postures, severe postural } \\
\text { instability, asymmetric Parkinsonism }\end{array}$ & $\begin{array}{l}\text { - Anti-TPO antibody titers raised to } 660 \\
\mathrm{IU} / \mathrm{ml}\end{array}$ & - No data & - 66-year-old female \\
\hline
\end{tabular}

ICA - internal carotid artery, MCA - middle cerebral artery, TPO - thyroid peroxidase, TDP-43 - transactive response DNA binding protein 43 kDa. 
to infarction of the left middle cerebral artery territory. In conclusion, damage of the areas of the brain involved in praxis, such as frontal and parietal cortices, thalamus, basal ganglia, and white matter tracts between them, as well as degeneration of the corticospinal tract can present as CBS. It is possible, that lag between stroke and symptoms' onset is present, as highrisk patients tend to experience silent ischemic incidents, which cumulatively deteriorate their neurological state. The presence of unexplained asymmetric spasticity and dystonia in the absence of cortical sensory loss, bradykinesia or cogwheel rigidity may be red flags for vascular CBS (Koga et al., 2019).

These clinical findings partially correspond with the research on functional SPECT imaging in CBS and related disorders, in which asymmetrical blood flow to the cerebral cortex, especially frontoparietal lobes, and basal ganglia in CBD was observed, in opposition to PSP, in which decreased blood flow was more of bilateral distribution (Zhang et al., 2001; Hossain et al., 2003; Ogawa et al., 2018). Okuda et al. (2000) share similar data, as more extensive and asymmetric blood flow reductions were observed by them in CBD than in PSP patients, with distribution in inferior prefrontal, sensorimotor, and posterior parietal cortices, but not in the subcortical regions.

\section{Autoimmune and Other Rare Backgrounds}

Additionally, vascular etiology of CBS may be attributable to antiphospholipid syndrome (APS) - autoimmune disease, which increases the general risk of thrombosis, also in the cerebral vessels (Carecchio et al., 2014). Despite the limited evidence of CBS in patients with APS (Ricarte et al., 2018), Morris et al. described a 44-year-old woman with Parkinsonism with hypomimia, gait disturbances, apraxia and a left-sided akinetic-rigid syndrome. Diagnostic investigation revealed, among others: the presence of lupus anticoagulant, elevated anticardiolipin antibodies and the presence of antinuclear antibodies. Abovementioned findings, accompanied by the MRI scans showing multiple infarcts in the hemispheres and basal ganglia, enabled to diagnose of primary APS with cortical and subcortical infarction, as a possible cause of CBS-like symptoms (Morris and Lees, 1999). Martino et al. (2006) described the second case-a 56-year-old woman with limb-kinetic apraxia and bradykinesia, whose brain MRI showed white matter changes, diffuse cerebral atrophy and several infarcts. Relatively similar medical case was described by Hashimoto et al., who presented a 53-year-old woman, who developed CBS due to APS secondary to SLE. Motor symptoms, which occurred in this patient were later attributed to the subcortical ischemic changes, cortical atrophy and several small infarctions in white matter; no basal ganglia infarcts were revealed (Hashimoto et al., 2018). One case of CBS associated with APS occurred without cerebral infarctions (Lee et al., 2014). It may be concluded that cerebrovascular lesions due to thrombosis are associated with CBS, while high levels of antiphospholipid antibodies, which damage vascular and attack the basal ganglia, contribute to development of CBS.

In addition, the literature reviews report the coexistence of CBS with Hashimoto encephalopathy. In the paper presented by Jain et al., a 70-year-old woman developed CBS symptoms in the course of Hashimoto encephalopathy (Table 1). An
MRI scan showed cortical ribboning. She had a high titer of antithyroid peroxidase antibodies (Jain and Khan, 2017). Sheetal et al. (2016) also described the case of the patient with a high level of antibodies and CBS-like symptoms. These data suggest that high level of anti TPO antibodies, which damage vascular endothelium and lead to perivascular infiltrations in cerebral cortex, may contribute to the development of CBS (Stojanovich et al., 2013; Ricarte et al., 2018). Nevertheless, CBS related to Hashimoto's encephalopathy was described only twice. It is possible that autoimmune processes, which lead to onset of vascular pathology and perivascular infiltrates, causes anoxia and brain edema, which further causes manifestations of CBS (Jain and Khan, 2017).

Vascular malformations have also been reported as a cause of CBS. Cavernous angioma described by Bihari et al. (2016) and dural arteriovenous fistula observed by Takase et al. (2017) were associated with neurological symptoms (Table 1). In patients, who developed symptoms of CBS associated with vascular malformations mechanism remains unclear (Bihari et al., 2016).

\section{Molecular and Genetic Studies}

Apart from the evidence acquired from the clinical practice it was observed that a specific endothelial growth factor may serve as a risk factor of CBS (Chahine et al., 2014). Jin et al. (2000) proved that VEGF may protect neurons from hypoxic or ischemic injury. The results of the study by Borroni, support a role for specific VEGF polymorphisms and haplotypes as risk factors for neurodegenerative diseases. Also, this study suggests the key role of genetic background in CBS pathogenesis proving that AGG (-2578C/A, -1190G/A, -1154G/A) haplotype carriers had a 6-fold increased risk to develop CBS than non-carriers. These data suggest that specific genetic variations of VEGF are a predisposing risk factor for CBS (Borroni et al., 2010).

\section{DISCUSSION}

\section{Clinical Perspective}

According to our research, vascular CBS, despite being relatively uncommon, should be considered in the differential diagnosis in patients with possible diagnosis of CBD and other neurodegenerative diseases. There are several indicators, which can implicate different than neurodegenerative etiology of CBS, vascular one included. Patients with vascular CBS tend to present a rapid onset of the symptoms, comparing to primarily insidious clinical phenotype of CBD. Moreover, their neurological state may deteriorate in a precipitous manner, as subsequent vascular episodes occur (Engelen et al., 2011). The presence of the time gap between a stroke and the appearance of neurological symptoms should not be perceived as an argument against vascular basis of CBS, as additional silent cerebrovascular accidents, typical for high-risk patients, may collectively contribute to exacerbation of their health state (Koga et al., 2019). According to our review, there is no typical clinical phenotype for vascular CBS, as patients experience a wide range of symptoms, from motor abnormalities to higher cortical dysfunctions. Nevertheless, it can be observed 
that individuals from this group are more likely to suffer from hypertension, dyslipidemia and diabetes mellitus; also, they often have a history of ischemic incidents and vascular disease (Table 1). Additionally, vascular etiology of CBS should be taken into consideration when the clinical manifestation includes other than typical CBS symptoms, as their presence may arise from cerebrovascular disease localized in various brain regions simultaneously (Morris and Lees, 1999; Martino et al., 2006). In spite of the fact that vascular CBS results from often irreversible brain damage, it is possible for some patients to improve after certain medical procedures, which enhance cerebral blood flow (Kim et al., 2009). On the other hand, patients with vascular CBS show little to no therapeutic response to L-dopa treatment, similarly to patients with CBS (Marsili et al., 2016).

\section{CONCLUSION}

Based on the cited studies, we concluded that the main risk factors of vascular CBS are ischemic. All various vascular pathologies described in this article lead to the conclusion that cerebral hypoperfusion can play a significant role in neuropathological changes, whose clinical manifestations can be various, CBS included. Nevertheless, it should be mentioned that the underlying disease may coexist with other pathologies, which do not necessarily influence its course or severity. Similarly, the number of lesions in the brain may not correlate with the severity of clinical manifestation. Many co-pathologies were described in CBD and PSP and pure syndromes in these neurodegenerative diseases are rare, but it is suspected that the rate of disease progression and course of main symptoms mostly depends on tau pathology (Jecmenica Lukic et al., 2020; Robinson et al., 2020). Coexistence of multiple possible causes of clinical symptoms hinders the diagnostic process and makes the evaluation of their

\section{REFERENCES}

Abe, Y., Kimura, N., Goto, M., Aso, Y., and Matsubara, E. (2016). Brain perfusion in corticobasal syndrome with progressive aphasia. Dement. Geriatr. Cogn. Dis. Extra. 6, 133-141. doi: 10.1159/000443329

Ali, F., and Josephs, K. A. (2018). Corticobasal degeneration: key emerging issues. J. Neurol. 265, 439-445. doi: 10.1007/s00415-017-8644-3

Arendt, T., Stieler, J. T., and Holzer, M. (2016). Tau and tauopathies. Brain Res. Bull. 126, 238-292.

Armstrong, M. J., Litvan, I., Lang, A. E., Bak, T. H., Bhatia, K. P., Borroni, B., et al. (2013). Criteria for the diagnosis of corticobasal degeneration. Neurology 80, 496-503.

Baborie, A., Griffiths, T. D., Jaros, E., Mckeith, I. G., Burn, D. J., Richardson, A., et al. (2011). Pathological correlates of frontotemporal lobar degeneration in the elderly. Acta Neuropathol. 121, 365-371.

Bihari, J., Hornyák, C., Szöke, K., Vajda, J., Bagó, A. G., Várallyay, G., et al. (2016). Corticobasal syndrome due to superficial siderosis caused by thalamic cavernoma. J. Neuropsychiatry Clin. Neurosci. 28, e15-e16.

Boeve, B. F. (2011). The multiple phenotypes of corticobasal syndrome and corticobasal degeneration: implications for further study. J. Mol. Neurosci. 45, 350-353. doi: 10.1007/s12031-0 11-9624-1

Borroni, B., Del Bo, R., Goldwurm, S., Archetti, S., Bonvicini, C., Agosti, C., et al. (2010). VEGF haplotypes are associated with increased risk to progressive significance troublesome. Another limitation of our study is the absence of post-mortem pathological examination in the majority of cited studies, which precludes assessing the real contribution of neurodegeneration in the clinical picture of presented patients. Nonetheless, our study has a chance to broaden the knowledge in a field of CBS pathogenesis and revise the way movement disorders are perceived. Presumably, the analysis of the holistic picture of coexisting symptoms, co-pathologies and genetic polymorphisms may improve the diagnostic process (Robinson et al., 2020). The importance of our paper derives from the fact that the prevalence of vascular incidents is high in the population, but rarely they are associated with CBS clinical phenotype. In addition to limited measures to confirm CBD diagnosis, which is commonly perceived as the main cause of CBS, it can lead to certain extent of misdiagnosis. We are positive that our research will encourage the Clinicians to consider vascular etiology in patients with CBS and consequently provide them with appropriate medical care. Moreover, as possible ways of vascular incidents' prevention exist, our research, compelling attention to vascular background, will hopefully contribute to the reduction of the number of patients with CBS.

\section{AUTHOR CONTRIBUTIONS}

$\mathrm{AD}$ involved in the study design, data analysis, review of the literature, writing - original draft preparation, writing - review and editing, and final acceptance. KW, KS, and JP involved in the data analysis, review of the literature, writing - original draft preparation, and writing - review and editing. PA involved in the study design, writing - review and editing, supervision, and final acceptance. All authors contributed to the article and approved the submitted version.

supranuclear palsy and corticobasal syndrome. J. Alzheimers Dis. 21, 87-94. doi: 10.3233/jad-2010-091615

Broce, I. J., Tan, C. H., Fan, C. C., Jansen, I., Savage, J. E., Witoelar, A., et al. (2019). Dissecting the genetic relationship between cardiovascular risk factors and Alzheimer's disease. Acta Neuropathol. 137, 209-226.

Carecchio, M., Cantello, R., and Comi, C. (2014). Revisiting the molecular mechanism of neurological manifestations in antiphospholipid syndrome: beyond vascular damage. J. Immunol. Res. 2014:239398.

Chahine, L. M., Rebeiz, T., Rebeiz, J. J., Grossman, M., and Gross, R. G. (2014). Corticobasal syndrome: five new things. Neurol. Clin. Pract. 4, 304-312. doi: 10.1212/cpj.0000000000000026

Chand, P., Grafman, J., Dickson, D., Ishizawa, K., and Litvan, I. (2006). Alzheimer's disease presenting as corticobasal syndrome. Mov. Disord. 21, 2018-2022.

De La Torre, J. (2018). The vascular hypothesis of alzheimer's disease: a key to preclinical prediction of dementia using neuroimaging. J. Alzheimers Dis. 63, 35-52. doi: 10.3233/jad-180004

De Reuck, J. L., Deramecourt, V., Cordonnier, C., Leys, D., Pasquier, F., and Maurage, C. A. (2012). Cerebrovascular lesions in patients with frontotemporal lobar degeneration: a neuropathological study. Neurodegener Dis. 9, 170-175. doi: 10.1 $159 / 000335447$

Di Stasio, F., Suppa, A., Marsili, L., Upadhyay, N., Asci, F., Bologna, M., et al. (2019). Corticobasal syndrome: neuroimaging and neurophysiological advances. Eur. J. Neurol. 26, 701-e752. 
Díaz-Ruiz, C., Wang, J., Ksiezak-Reding, H., Ho, L., Qian, X., Humala, N., et al. (2009). Role of hypertension in aggravating abeta neuropathology of AD type and tau-mediated motor impairment. Cardiovasc. Psychiatry Neurol. 2009:107286.

Engelen, M., Westhoff, D., De Gans, J., and Nederkoorn, P. J. (2011). A 64-year old man presenting with carotid artery occlusion and corticobasal syndrome: a case report. J. Med. Case Rep. 5:357.

Gibb, W. R., Luthert, P. J., and Marsden, C. D. (1989). Corticobasal degeneration. Brain 112(Pt 5), 1171-1192.

Goedert, M., Eisenberg, D. S., and Crowther, R. A. (2017). Propagation of tau aggregates and neurodegeneration. Annu. Rev. Neurosci. 40, 189-210. doi: 10.1146/annurev-neuro-072116-031153

Grijalvo-Perez, A. M., and Litvan, I. (2014). Corticobasal degeneration. Semin. Neurol. 34, 160-173.

Hashimoto, R., Ogawa, T., Tagawa, A., and Kato, H. (2018). Corticobasal syndrome associated with antiphospholipid syndrome secondary to systemic lupus erythematosus. Case Rep. Neurol. Med. 2018:5872638.

Hossain, A. K., Murata, Y., Zhang, L., Taura, S., Saitoh, Y., Mizusawa, H., et al. (2003). Brain perfusion SPECT in patients with corticobasal degeneration: analysis using statistical parametric mapping. Mov. Disord. 18, 697-703. doi: 10.1002/mds. 10415

Hu, W. T., Rippon, G. W., Boeve, B. F., Knopman, D. S., Petersen, R. C., Parisi, J. E., et al. (2009). Alzheimer's disease and corticobasal degeneration presenting as corticobasal syndrome. Mov. Disord. 24, 1375-1379.

Irwin, D. J. (2016). Tauopathies as clinicopathological entities. Parkinsonism. Relat. Disord. 22(Suppl. 1), S29-S33.

Jain, R., and Khan, I. (2017). Corticobasal syndrome like presentation of Hashimoto encephalopathy with cortical ribboning. Indian J. Med. Special. 8, 209-212. doi: 10.1016/j.injms.2017.08.003

Jecmenica Lukic, M., Kurz, C., Respondek, G., Grau-Rivera, O., Compta, Y., Gelpi, E., et al. (2020). Copathology in progressive supranuclear palsy: does it matter? Mov. Disord. 35, 984-993.

Jin, K. L., Mao, X. O., and Greenberg, D. A. (2000). Vascular endothelial growth factor: direct neuroprotective effect in in vitro ischemia. Proc. Natl. Acad. Sci. U.S.A. 97, 10242-10247. doi: 10.1073/pnas.97.18.10242

Josephs, K. A., Ishizawa, T., Tsuboi, Y., Cookson, N., and Dickson, D. W. (2002). A clinicopathological study of vascular progressive supranuclear palsy: a multiinfarct disorder presenting as progressive supranuclear palsy. Arch. Neurol. 59, 1597-1601. doi: 10.1001/archneur.59.10.1597

Josephs, K. A., Whitwell, J. L., Boeve, B. F., Knopman, D. S., Petersen, R. C., $\mathrm{Hu}, \mathrm{W} . \mathrm{T}$., et al. (2010). Anatomical differences between CBS-corticobasal degeneration and CBS-Alzheimer's disease. Mov. Disord. 25, 1246-1252. doi: $10.1002 / \mathrm{mds} .23062$

Khan, S., and Davies, I. B. (2008). Hypoxia and Alzheimer disease. CMAJ 178, 1687-1688. doi: 10.1503/cmaj.1080038

Kim, Y. D., Kim, J. S., Lee, E. S., Yang, D. W., Lee, K. S., and Kim, Y. I. (2009). Progressive "vascular" corticobasal syndrome due to bilateral ischemic hemispheric lesions. Intern. Med. 48, 1699-1702. doi: 10.2169/ internalmedicine.48.2415

Koga, S., Roemer, S. F., Kasanuki, K., and Dickson, D. W. (2019). Cerebrovascular pathology presenting as corticobasal syndrome: an autopsy case series of “vascular CBS". Parkinsonism. Relat. Disord. 68, 79-84. doi: 10.1016/j. parkreldis.2019.09.001

Kovacs, G. G. (2015). Invited review: neuropathology of tauopathies: principles and practice. Neuropathol. Appl. Neurobiol. 41, 3-23. doi: 10.1111/nan.12208

Kovacs, G. G. (2017). Tauopathies. Handb. Clin. Neurol. 145, 355-368.

Kreisler, A., Mastain, B., Tison, F., Fénelon, G., and Destée, A. (2007). [Multi-infarct disorder presenting as corticobasal degeneration (DCB): vascular pseudo-corticobasal degeneration?]. Rev. Neurol. (Paris) 163, 11911199.

Lee, D. W., Eum, S. W., Moon, C. O., Ma, H. I., and Kim, Y. J. (2014). Corticobasal syndrome associated with antiphospholipid syndrome without cerebral infarction. Neurology 82, 730-731. doi: 10.1212/wnl.0000000000000152

Liesz, A. (2019). The vascular side of Alzheimer's disease. Science 365, 223-224.

Ling, H., O'sullivan, S. S., Holton, J. L., Revesz, T., Massey, L. A., Williams, D. R., et al. (2010). Does corticobasal degeneration exist? Clinicopathol. Eval. Brain 133, 2045-2057. doi: 10.1093/brain/awq123
Marques, A., Bourgois, N., Vidal, T., Ferrier, A., Mathais, S., Merlin, C., et al. (2018). Subacute corticobasal syndrome following internal carotid endarterectomy. Rev. Neurol. (Paris) 174, 157-161. doi: 10.1016/j.neurol.2017.06.017

Marsili, L., Dickson, D. W., and Espay, A. J. (2018). Globular glial tauopathy may be mistaken for corticobasal syndrome-pointers for the clinician. Mov. Disord. Clin. Pract. 5, 439-441. doi: 10.1002/mdc3.12634

Marsili, L., Suppa, A., Berardelli, A., and Colosimo, C. (2016). Therapeutic interventions in parkinsonism: corticobasal degeneration. Parkinsonism. Relat. Disord. 22(Suppl. 1), S96-S100.

Martino, D., Chew, N. K., Mir, P., Edwards, M. J., Quinn, N. P., and Bhatia, K. P. (2006). Atypical movement disorders in antiphospholipid syndrome. Mov. Disord. 21, 944-949. doi: 10.1002/mds. 20842

Mathew, R., Bak, T. H., and Hodges, J. R. (2011). Screening for cognitive dysfunction in corticobasal syndrome: utility of Addenbrooke's cognitive examination. Dement. Geriatr. Cogn. Disord. 31, 254-258. doi: 10.1159/ 000327169

Miyaji, Y., Koyama, K., Kurokawa, T., Mitomi, M., Suzuki, Y., and Kuroiwa, Y. (2013). Vascular corticobasal syndrome caused by unilateral internal carotid artery occlusion. J. Stroke Cerebrovasc. Dis. 22, 1193-1195. doi: 10.1016/j. jstrokecerebrovasdis.2012.07.005

Mokri, B., Ahlskog, J. E., Fulgham, J. R., and Matsumoto, J. Y. (2004). Syndrome resembling PSP after surgical repair of ascending aorta dissection or aneurysm. Neurology 62, 971-973. doi: 10.1212/01.wnl.0000115170.40838.9b

Morris, H. R., and Lees, A. J. (1999). Primary antiphospholipid syndrome presenting as a corticobasal degeneration syndrome. Mov. Disord. 14, 530-532. doi: 10.1002/1531-8257(199905)14:3<530::aid-mds1030>3.0.co;2-8

Mulroy, E., Jaunmuktane, Z., Balint, B., Erro, R., Latorre, A., and Bhatia, K. P. (2020). Some new and unexpected tauopathies in movement disorders. Mov. Disord. Clin. Pract. 7, 616-626. doi: 10.1002/mdc3.12995

Ogawa, T., Fujii, S., Kuya, K., Kitao, S. I., Shinohara, Y., Ishibashi, M., et al. (2018). Role of neuroimaging on differentiation of parkinson's disease and its related diseases. Yonago Acta Med. 61, 145-155. doi: 10.33160/yam.2018.09.001

Okuda, B., Tachibana, H., Kawabata, K., Takeda, M., and Sugita, M. (2000). Cerebral blood flow in corticobasal degeneration and progressive supranuclear palsy. Alzheimer Dis. Assoc. Disord. 14, 46-52. doi: 10.1097/00002093200001000-00006

Parmera, J. B., Rodriguez, R. D., Studart Neto, A., Nitrini, R., and Brucki, S. M. D. (2016). Corticobasal syndrome: a diagnostic conundrum. Dement. Neuropsychol. 10, 267-275. doi: 10.1590/s1980-5764-2016dn1004003

Peters, S., Eising, E. G., Przuntek, H., and Müller, T. (2001). Vascular parkinsonism: a case report and review of the literature. J. Clin. Neurosci. 8, 268-271. doi: 10.1054/jocn.2000.0807

Rabadia, S. V., Litvan, I., Juncos, J., Bordelon, Y., Riley, D. E., Standaert, D., et al. (2019). Hypertension and progressive supranuclear palsy. Parkinsonism. Relat. Disord. 66, 166-170.

Rebeiz, J. J., Kolodny, E. H., and Richardson, E. P. (1967). Corticodentatonigral degeneration with neuronal achromasia: a progressive disorder of late adult life. Trans Am. Neurol. Assoc. 92, 23-26.

Rebeiz, J. J., Kolodny, E. H., and Richardson, E. P. (1968). Corticodentatonigral degeneration with neuronal achromasia. Arch. Neurol. 18, 20-33. doi: 10.1001/ archneur.1968.00470310034003

Respondek, G., Grimm, M. J., Piot, I., Arzberger, T., Compta, Y., Englund, E., et al. (2020). Validation of the movement disorder society criteria for the diagnosis of 4-repeat tauopathies. Mov. Disord 35, 171-176.

Ricarte, I. F., Dutra, L. A., Abrantes, F. F., Toso, F. F., Barsottini, O. G. P., Silva, G. S., et al. (2018). Neurologic manifestations of antiphospholipid syndrome. Lupus 27, 1404-1414.

Robinson, J. L., Yan, N., Caswell, C., Xie, S. X., Suh, E., Van Deerlin, V. M., et al. (2020). Primary tau pathology, not copathology, correlates with clinical symptoms in PSP and CBD. J. Neuropathol. Exp. Neurol. 79, 296-304. doi: 10.1093/jnen/nlz141

Salminen, A., Kauppinen, A., and Kaarniranta, K. (2017). Hypoxia/ischemia activate processing of amyloid precursor protein: impact of vascular dysfunction in the pathogenesis of alzheimer's disease. J. Neurochem. 140, 536-549. doi: 10.1111/jnc.13932

Saranza, G. M., Whitwell, J. L., Kovacs, G. G., and Lang, A. E. (2019). Corticobasal degeneration. Int. Rev. Neurobiol. 149, 87-136. 
Sheetal, S. K., Mathew, R., and Peethambaran, B. (2016). Hashimoto's encephalopathy as a treatable cause of corticobasal disease. Ann. Indian Acad. Neurol. 19, 285-286. doi: 10.4103/0972-2327.176859

Stojanovich, L., Kontic, M., Smiljanic, D., Djokovic, A., Stamenkovic, B., and Marisavljevic, D. (2013). Association between non-thrombotic neurological and cardiac manifestations in patients with antiphospholipid syndrome. Clin. Exp. Rheumatol. 31, 756-760.

Takase, K. I., Matsumoto, S., Nishi, H., and Nakahara, I. (2017). A case of superior sagittal sinus intracranial dural arteriovenous fistula mimicking corticobasal syndrome. J. Neurol. Sci. 376, 91-92. doi: 10.1016/j.jns.2017.03.004

Tan, C. C., Zhang, X. Y., Tan, L., and Yu, J. T. (2018). Tauopathies: mechanisms and therapeutic strategies. J. Alzheimers Dis. 61, 487-508. doi: 10.3233/jad-17 0187

Thal, D. R., Von Arnim, C. A., Griffin, W. S., Mrak, R. E., Walker, L., Attems, J., et al. (2015). Frontotemporal lobar degeneration FTLD-tau: preclinical lesions, vascular, and Alzheimer-related co-pathologies. J. Neural. Transm. (Vienna) 122, 1007-1018. doi: 10.1007/s00702-014-1360-6

Tisel, S. M., Ahlskog, J. E., Duffy, J. R., Matsumoto, J. Y., and Josephs, K. A. (2020). PSP-like syndrome after aortic surgery in adults (Mokri syndrome). Neurol. Clin. Pract. 10, 245-254. doi: 10.1212/cpj.0000000000000708

Toledo, J. B., Arnold, S. E., Raible, K., Brettschneider, J., Xie, S. X., Grossman, M., et al. (2013). Contribution of cerebrovascular disease in autopsy confirmed neurodegenerative disease cases in the National Alzheimer's Coordinating Centre. Brain 136, 2697-2706. doi: 10.1093/brain/awt188

Vitt, J. R., Hamedani, A. G., Horn, S., Gannon, K. P., Price, R. S., and Greene, M. (2020). Acquired hemicerebral atrophy secondary to chronic internal carotid steno-occlusive disease: a case series. Neurohospitalist 10, 38-42. doi: 10.1177/ 1941874419859762

Winikates, J., and Jankovic, J. (1994). Vascular progressive supranuclear palsy. J. Neural. Transm. Suppl. 42, 189-201. doi: 10.1007/978-3-7091-6641-3_15

Yamauchi, H., Kagawa, S., Kishibe, Y., Takahashi, M., and Higashi, T. (2017). Progressive cortical neuronal damage and extracranial-intracranial bypass surgery in patients with misery perfusion. AJNR Am. J. Neuroradiol. 38, 935941. doi: 10.3174/ajnr.a5110

Yamauchi, H., Kudoh, T., Kishibe, Y., Iwasaki, J., and Kagawa, S. (2007). Selective neuronal damage and chronic hemodynamic cerebral ischemia. Ann. Neurol. 61, 454-465. doi: 10.1002/ana.21104

Zhang, L., Murata, Y., Ishida, R., Saitoh, Y., Mizusawa, H., and Shibuya, H. (2001). Differentiating between progressive supranuclear palsy and corticobasal degeneration by brain perfusion SPET. Nucl. Med. Commun. 22, 767-772 doi: 10.1097/00006231-200107000-00007

Conflict of Interest: The authors declare that the research was conducted in the absence of any commercial or financial relationships that could be construed as a potential conflict of interest.

Copyright (c) 2021 Dunalska, Pikul, Schok, Wiejak and Alster. This is an open-access article distributed under the terms of the Creative Commons Attribution License (CC BY). The use, distribution or reproduction in other forums is permitted, provided the original author(s) and the copyright owner(s) are credited and that the original publication in this journal is cited, in accordance with accepted academic practice. No use, distribution or reproduction is permitted which does not comply with these terms. 